\title{
Sensing of Dynamic Loads in the Open-Cast Mine Combine
}

\author{
Dilshad Kouziyev ${ }^{1}$, Aleksandr Krivenko ${ }^{1}$, Daria Chezganova ${ }^{1}$, and Blumensteiun Valeriy ${ }^{2}$ \\ ${ }^{1}$ NUST "MISiS” Mining Equipment, Transport and Mashine Building Department, 119991, Moscow, \\ Russian Federation \\ ${ }^{2}$ T.F. Gorbachev Kuzbass State Technical University, 650000, Kemerovo, Russian Federation
}

\begin{abstract}
The open-cast mine combine's system was analyzed in order to determine the system's dynamic characteristics and behavior. The analysis has established that rigidity of the working element's transmission of the open-cast mine combine is a function of torsional stiffness of the "pump to - hydraulic motor" hydraulic transmission.
\end{abstract}

\section{Introduction}

The experience of research in dynamics of mining machinery /1, 2, 3, 4, 5/ shows that at the time of vibration analysis and dynamic load assessment, a machine at large corresponds generally to lumped masses, linked together by imponderable resilient elements, exposed to external forces.

To a significant extent, validity of the analysis of the surface miner's characteristics is determined by actual properties of the system under study, exhaustively reflected by the dynamic model. Consequently, the dynamic model development is one of the most important stages of analysis of the machine's characteristics and behavior /6, 7, 8/.

\section{Objects and research methods}

Any machine, including a mining one, can be conceived of as a mechanical model, comprised of single lumped masses $m_{1}, m_{2} \ldots m_{i} \ldots m_{n}$ or inertia moments $\dot{I}_{1}, \dot{I}_{2} \ldots \dot{I}_{i} \ldots \dot{I}_{n}$, linked together by resilient elements. In parallel, it is assumed that the resilient elements are imponderable and characterized by the constant factors of rigidity $K_{1}, K_{2} \ldots K_{i} \ldots K_{n}$. As a result, a physical machine is replaced by a reduced equivalent system, which must correctly reflect the machine's key dynamic characteristics. Then, development of a design model comes down to determination of reduced lumped masses of progressively moving elements or inertia moments of the machine's rotating elements, as well as of rigidity of the key elastic linkages and the reduced loads, acting upon the system.

The solid body's moment of inertia about axis represents a measure of inertia of this body during its swinging motion about the above axis, which may pass through the above body or may be external to it /9/. The inertia moment sensing can be implemented through 
the use of analytical method and by experiment. The analytical method can be applied to determination of inertia moments of regular shaped homogeneous solids.

\section{Research results and discussion}

The inertia moments of cutting screw conveyor of the open-cast mine combine's working element is determined from the following formula:

$$
\dot{I}=V_{\Delta} \gamma \frac{D_{c p}}{4} k_{3},
$$

$V_{\Delta}$ - volume of the cutting screw conveyor's flights amounting to:

$$
\mathrm{V}_{\Delta}=\mathrm{F}_{\Delta} \mathrm{S}_{\Delta} \mathrm{z} \frac{\mathrm{B}}{\mathrm{t}}, \mathrm{m}^{3},
$$

where: $F_{\Delta}$ - triangle section of the cutting screw conveyor having a cutting structure with its seat of $-l(\mathrm{~m})$ and the height of $\frac{\mathrm{D}_{\max }-\mathrm{D}_{\min }}{2}(\mathrm{~m})$ :

$$
F_{\Delta}=\frac{D_{\max }-D_{\min }}{2} l, \mathrm{~m}^{2} ;
$$

$S_{\Delta}$ - the cutting screw conveyor's one-flight length, which is equal to hypotenuse of triangle, of which one leg is equal to the circumference length - $\pi D_{c p}$ of auger-cutter drum, while another one $t$ - to working element's helix lead.

$$
\mathrm{S}_{\Delta}=\frac{\pi \mathrm{D}_{\mathrm{cp}}}{\operatorname{Cos} \alpha}, \mathrm{m}
$$

$z$ - number of Archimedean screws, one each $(z=2)$

$$
\mathrm{t}=\frac{\mathrm{B}}{2}
$$

$\gamma$ - material density of cutting screw conveyors, $\gamma=7.8 \cdot 10^{3} \mathrm{~kg} / \mathrm{m}^{3}$;

$k_{3}$ - the coefficient that corrects for irregularity of the cutting screw conveyor's flight section over its flight, $k_{3}=0.5$.

Finally, the inertia moment of screw conveyors with regard for (2), (3), (4) and (5) equal to the value, expressed by:

$$
\dot{I}=\frac{\pi \cdot l \gamma}{32 \operatorname{Cos} \alpha} \cdot\left(D_{\max }^{2}-D_{\min }^{2}\right) \cdot\left(D_{\text {max }}+D_{\min }\right)^{2}, k g m^{2} .
$$

The moment of inertia of the sidewall, planet gear casing and hydraulic motor shaft is determined from the following formula:

$$
\dot{\mathrm{I}}_{\mathrm{i}}=\gamma \frac{\pi \cdot 1_{\mathrm{i}}}{32}\left(\mathrm{D}_{\operatorname{maxi}}^{4}-\mathrm{D}_{\operatorname{mini}}^{4}\right), k g m^{2},
$$


In solving dynamic problems, a need arises to reduce masses, rigidities and effective loads to one of the shafts of equivalent model. Thus, the inertia moment, reduced to the hydraulic motor shaft, would be equal to the following value:

$$
\dot{\mathrm{I}}=\sum_{1}^{\mathrm{n}} \mathrm{I}_{\mathrm{i}} \mathrm{i}_{\mathrm{i}}, k g m^{2},
$$

where: $i_{i}$ - gearing ratio of the transmission element to the hydraulic motor shaft.

The factor of rigidity represents the ratio between the effective load (force or moment) and the value of strain, induced by the above load /10/. Correspondingly, the rigidity factor is measured in N/v (C) under linear strain, while under torsional strain - in Nm/rad $(K)$. While determining total structural rigidity the structure's most collapsible elements can be separated, and alternatively, in cases when they may be considered as standard elements, testing of their rigidity involves no difficulties.

Mechanical compliance (rigidity reciprocal value) of the transmission element of the augercutter working element was determined from the following formula:

$$
\frac{1}{\mathrm{~K}_{\mathrm{i}}}=\frac{32}{\pi \mathrm{G}} \cdot \frac{\mathrm{l}_{\mathrm{i}}}{\mathrm{D}_{\operatorname{maxi}}^{4}-\mathrm{D}_{\min i}^{4}}, \mathrm{rad} / \mathrm{Nm},
$$

where: $K_{i}$ - rigidity $i$ - of this transmission element, $\mathrm{Nm} / \mathrm{rad}$;

$G$ - shear modulus, Pa, equal to:

$$
G=\frac{E_{C}}{2\left(1+v_{I}\right)},
$$

where: $E_{c}$ - the elastic modulus of the transmission element material, $E_{c}=2,1 \cdot 10^{11} \mathrm{~Pa} / 50$;

$v_{n}$ - the Poisson ratio, which, for steel, is equal to: $v_{n}=0.3$.

Work $/ 11 /$ provides mechanical compliance values, calculated using formula (8), given that the value of steel shear modulus - $G$ is assumed to be equal to $0.8 \cdot 10^{11} \mathrm{~Pa}$, while mechanical compliance of flights of the cutting screw conveyors is decreased by the value of the coefficient $-k_{3}$, which takes into account irregularity of their section over the length. Reduction of the mechanical compliance values of the transmission mechanical section elements of auger-cutter working element to the hydraulic motor shaft subject to gearing ratios $-i_{i}$ (with no account for frictional losses) is completed according to the diagram (Fig. $1)$.

Thus, mechanical compliance of transmission of the auger-cutter working element, reduced to the hydraulic motor shaft, is determined from the following formula:

$$
1 / \mathrm{K}_{\mathrm{TP}}=\sum_{\mathrm{i}}^{\text {III }} 1 / \mathrm{K}_{\mathrm{i}}, \mathrm{rad} / \mathrm{Nm},
$$

where: $K_{m p}$ - transmission rigidity of auger-cutter working element, reduced to the hydraulic motor shaft, $\mathrm{Nm} / \mathrm{rad}$;

$1 / K_{I}-$ total reduced sidewall mechanical compliance of the cutter drum with cutting screw conveyors and gear box cases, $\mathrm{rad} / \mathrm{Nm}$;

$1 / K_{I I}-$ total reduced mechanical compliance of the satellite gears, $\mathrm{rad} / \mathrm{Nm}$;

$1 / K_{I I I}$ - total reduced mechanical compliance of the hydraulic motor's rotor with pinion shaft, $\mathrm{rad} / \mathrm{Nm}$. 


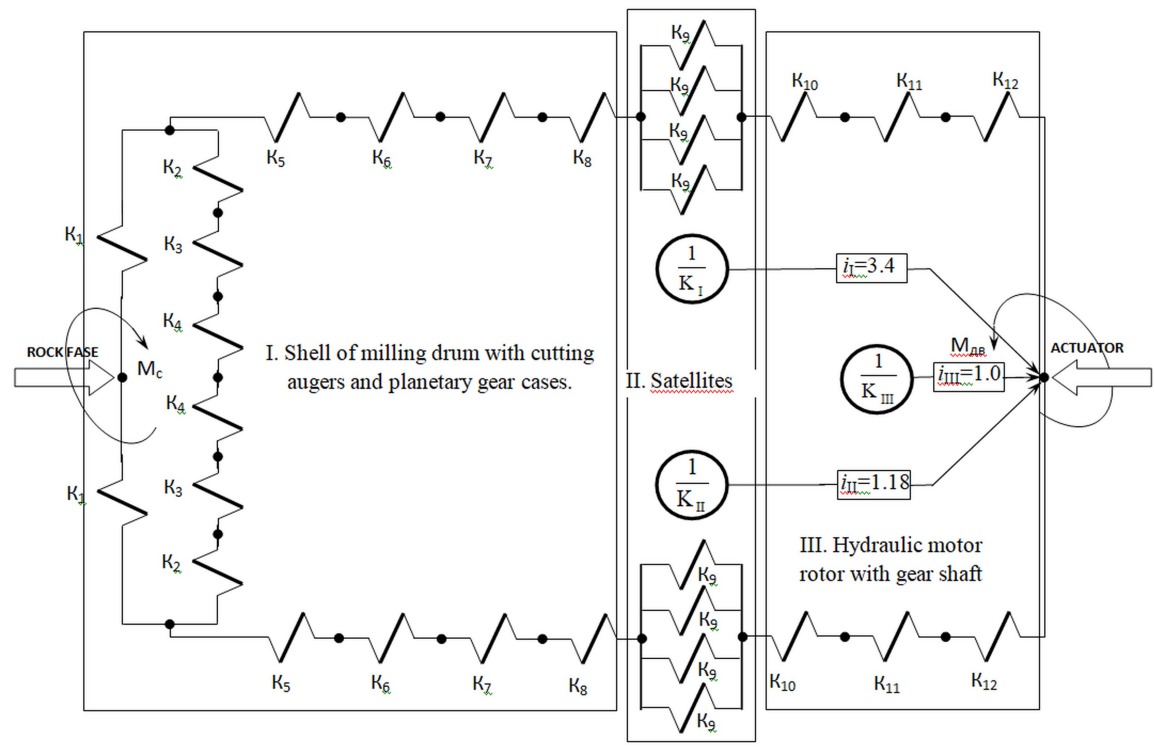

Fig. 1. Diagram of bringing the stiffness of the elements of the mechanical part of the transmission of the screw-milling working body to the hydraulic motor shaft.

\section{Conclusion}

Total mechanical compliance of transmission of the auger-cutter working element reduced to the hydraulic motor shaft (see. $/ 5 /$ ) is equal to:

$$
\frac{1}{K_{T P}}=(0.0017+0.0261+1009.8350) \cdot 10-15=1009.8628 \cdot 10^{-15} \mathrm{rad} / \mathrm{Nm},
$$

Rigidity of transmission of the auger-cutter working element reduced to the hydraulic motor shaft will amount to the value of:

$$
K_{T P}=9902 \cdot 10^{2} \mathrm{KNm} / \mathrm{rad}
$$

Comparison of the results obtained with the rigidity of the hydraulic transmission $\backslash 5,9 \backslash$ established that, the transmission drive rigidity of the open-cast mine combine 's augercutter working element is determined by torsional stiffness of the "pump-to-hydraulic motor" hydraulic transmission.

\section{References}

1. V.V. Gabov, D.A. Zadkov, Journal of Physics: Conference Series, 1015:52007, 1 (2018)

2. A.V. Stebnev, D.A. Zadkov, V.V. Gabov, S.G. Mukhortikov, Eurasian mining, 2, 28 (2017)

3. V.V. Gabov, D.A. Zadkov, Eurasian mining, 1, 37 (2016)

4. D.A. Yungmeister, S.E. Ivanov, A.I. Isaev, IOP Conference Series: Materials Science and Engineering, 327:2, 022050 (2018) 
5. D. Szurgacz, E3S Web Conf., 29, 00007 (2018)

6. R.N. Safiullin, A.S. Afanasyev, IOP Conference Series: Earth and Environmental Science, 194:7, 072011, (2018)

7. A.S. Afanasyev, N.V. Chudakova, Journal of Physics: Conference Series, 1118:1, $012001(2018)$

8. A.M. Keropyan, L.I. Kantovich, B.V. Voronin, D.A. Kuziev, V.V. Zotov, IOP Conference Series: Earth and Environmental Science, 87, 1 (2017)

9. V.V. Buevich, V.V. Gabov, D.A. Zadkov, P.A. Vasileva, Eurasian mining, 2, 11 (2015)

10. D. Yungmeister, S. Lavrenko, D. Shishliannikov, G. Iusupov, International Journal of Applied Engineering Research, 10:7, 16409 (2015)

11. D.A. Kouziev, I.N. Klementeva, GIAB, 2, 123 (2019) 